\title{
Blepharophimosis-intellectual disability syndrome, SBBYS type
}

INSERM

\section{Source}

INSERM. (1999). Orphanet: an online rare disease and orphan drug data base. Blepharophimosis-intellectual disability syndrome, SBBYS type. ORPHA:3047

Blepharophimosis-intellectual disability syndrome, SBBYS type is characterised by the association of congenital hypothyroidism, facial dysmorphism (microcephaly, blepharophimosis, a bulbous nose, thin lip, low-set ears and micrognathia), postaxial polydactyly and severe intellectual deficit. Less than 20 cases have been reported so far. Cryptorchidism is present in affected males. Some patients also have cardiac anomalies (interventricular communication), hypotonia and growth delay. Autosomal recessive inheritance has been suggested. 